\title{
CHICAS MUERTAS, DE SELVA ALMADA: TRÊS ASSASSINATOS E O SILENCIAMENTO DA VIOLÊNCIA CONTRA AS MULHERES
}

\author{
Regina Kohlrausch* \\ Maria Edilene de Paula Kobolt ${ }^{* *}$
}

\begin{abstract}
RESUMO: O presente artigo volta-se para a análise da obra Chicas muertas (2014), de Selva Almada, visando mostrar de que maneira se cumpre a função social da arte, conforme Candido (2000), na voz dessa escritora argentina e também indicar como exemplo do processo de ocupação de espaço pela mulher no universo literário. Apresentam-se ainda dados biográficos situando-a também como mulher que se inclui na própria obra ficcional.
\end{abstract}

Palavras-chave: Autoria feminina. Selva Almada. Chicas muertas.

\section{Os murmúrios latentes}

Eu sempre tive pelas senhoras que fazem literatura - um atenorado respeito. As relações com uma poetisa são verdadeiros desastres impossíveis de remediar, mas que o galanteio social obriga a acoroçoar. Quando a femme de lettres deixa o verso e embarafusta por outras dependências da complicada arte de escrever, as relações passam à calamidade. [...] Por que escrevem essas senhoras? Ninguém o soube; ninguém o saberá. Com certeza porque não tinham mais o que fazer, como a Duquesa de Dino. Mas elas escrevem, escrevem.

João do Rio ${ }^{\mathrm{i}}$

A citação acima expressa, por um lado, o ponto de vista individual de João do Rio, e, por outro, o pensamento de certa forma coletivo, em relação à época, ou seja, início do século $\mathrm{XX}$, quando as mulheres seguiam (e ainda seguem) lutando por seu espaço numa sociedade patriarcal comandada pelo pai detentor de poder sobre seus dependentes, entre eles as mulheres: a esposa e a(s) filha(s). Além disso, é claramente perceptível a posição e atitude preconceituosas contra a mulher que escreve e que tenta colocar-se no mundo da literatura. Esta atitude torna-se comum para o período, uma vez que, não só na produção, mas também na crítica literária, a voz era predominantemente masculina, desprezando oportunidades de inserção da mulher também na sociedade letrada por eles constituída.

Os anos passaram e os questionamentos sobre o ingresso da mulher ou da autoria feminina na literatura continuam presentes nos estudos acadêmicos com o objetivo de recuperar o espaço negado e a invisibilidade do passado e garantir, no presente, a visibilidade das vozes em ação. Admitir que as escritoras pudessem ter alguma participação na formação da identidade nacional era inaceitável, pois iria contra o cânone instituído pela cultura patriarcal. De acordo com Zolin (2012, p.328), a mulher penetra na sociedade letrada em

\footnotetext{
* Pós-doutoramento em Estudos Literários na Universidade de Vigo, Espanha, com bolsa CAPES/Fundación Carolina. Professora titular, graduação e Pós-graduação da área de Letras, da Escola de Humanidades da PUCRS, atuando como Decana Associada da Escola de Humanidades e Membro da Comissão Coordenadora do PPGL da PUCRS. Graduação em Letras Português Espanhol e Respectivas Literaturas, Mestrado e Doutorado em Letras: Teoria da Literatura, pela Pontifícia Universidade Católica do Rio Grande do Sul (PUCRS). Membro do GT História da Literatura e Coordenadora do grupo de pesquisa Escritores Sulinos (CNPq).

E-mail: regina.kohlrausch@ pucrs.br

** Doutoranda em Letras: Teoria Literária pela Pontifícia Universidade Católica do Rio Grande do Sul (PUCRS). Bolsista CAPES/PROEX. Mestra em Linguística Aplicada pela Universidade do Vale do Rio dos Sinos (UNISINOS). Especialista em Tradução e Versão de Espanhol (UNIVERSIDADE GAMA FILHO). Professora de Língua Espanhola nomeada pelo Estado do Rio Grande do Sul. Integrante do Núcleo de Estudos sobre Tecnologias na Educação - NETE - coordenado pela Prof. Dra. Elaine Conte (UNILASALLE). Integrante do grupo de Estudos Acervo de Escritores Sulinos, da PUCRS, coordenado pela Professora Dra. Regina Kohlrausch.

E-mail: mariaedilenekobolt@gmail.com
}

IPOTESI, JUIZ DE FORA, v. 23, n. 2, p. 65-78, jul./dez. 2019 
consequência do feminismo que possibilitou sua atuação como literatas e também como críticas: "De um lado, a crítica literária, antes de domínio quase exclusivamente masculino, passou a ser praticada por mulheres; de outro, estas passaram a escrever mais como literatas, livres dos temores da rejeição e do escândalo" (ZOLIN, 2012, p.328).

Ao recorrermos à história para entendermos o percurso do feminino, observamos que os movimentos feministas na década de 60 foram constituídos por grupos mais informados e ativos que outras relevantes manifestações dos séculos XVIII e XIX. Em outras palavras, ampliou-se a discussão e a pesquisa acadêmica sobre o universo feminino, que oportunizou construir e reconstruir pressupostos epistemológicos que apresentassem a mulher numa relação de subalternidade em espaço particular. Descobriu-se, conforme Silva (2008, p. 226), que o universo feminino tinha muito a contribuir com o meio social, as mulheres tinham uma história e valia a pena compreender e buscar mais informações sobre elas. Esta "rebelião" feminina proporcionou a reconstrução da história das mulheres, entre elas a organizada por Del Priori (2001) em sua História das mulheres do Brasil, na qual "A história não é só delas, é também da família, da criança, do trabalho, da mídia, da literatura. É a história do seu corpo, da sua sexualidade, da violência que sofreram e que praticaram, da sua loucura, dos seus amores e dos seus sentimentos" (DEL PRIORI, 2008, p. 7).

Mulheres começaram a levantar questões da esfera social, por meio de suas obras, como, por exemplo, Simone de Beauvoir, em O segundo sexo: fatos e mitos (1970), na qual expõe sobre o reconhecimento da mulher por ela mesma. Famosa por sua frase "Não se nasce mulher, torna-se mulher", a autora disserta sobre o espaço que envolve o feminino, sinalizando para um conceito de uma nova mulher do século $\mathrm{XX}$, ou seja, aquela que não deve ser mais submissa e passiva. Posteriormente, continuando o questionamento acerca desse universo, Judith Butler, em Problemas de gênero: feminismo e subversão da identidade (2003), desconstrói o conceito de gênero mantido pela teoria feminista ao discutir a relação entre sexo e gênero. Para ela, que desenvolve reflexões acerca das conflagrações das ações feministas resultantes da identidade universal, a "identidade definida", defendida pelo movimento feminista em diálogo com a frase de Beauvoir, "não há nada em sua explicação que garanta que o 'ser' se torna mulher seja necessariamente fêmea”. (BUTLER, 2003, p. 27).

Em tempos atuais, em pleno século XXI, seguimos, necessariamente, por meio da leitura e da escrita, destacando a importância que o tema em torno do feminino tem e continuará tendo até que seja efetivamente reconhecido pela esfera social como ponto primordial para a construção de uma sociedade crítica, justa e desprovida de preconceitos de gênero. Provocar a discussão sobre as diferentes concepções femininas e realizar a leitura da literatura do passado e do presente torna-se, portanto, fundamental para alcançar essa visão crítica, justa e sem preconceitos da temática do feminino.

Para auxiliar esse olhar em torno do assunto que envolve literatura e mulher, convém visitar o site do Ministério da Cultura (BRASIL, 2016), que divulgou, com o título $\mathrm{Na}$ literatura, a mulher ainda não alcançou protagonismo ${ }^{i i}$, resultados originados da pesquisa realizada pela professora e pesquisadora Regina Dalcastgnè (Universidade de Brasília UNB), a qual teve como objetivo oportunizar um panorama que possibilitasse a compreensão do papel da mulher na literatura nacional contemporânea. Para isso, Dalcastgnè estudou 700 romances brasileiros contemporâneos, de 383 autores diferentes, divididos em dois espaços temporais: o primeiro de 1965 a 1979 e o segundo de 1990 a 2004, ampliado até 2014.

Os dados obtidos nessa análise são significativos e confirmam as diferenças sociais relacionadas ao sistema literário no que se refere à autoria e também à representação do feminino nas obras analisadas. Vejamos alguns números em relação à representatividade feminina como personagem: $79,8 \%$ são mulheres brancas, $81 \%$ heterossexual e $82,9 \%$ rica ou de classe média; em relação à autoria e ao protagonismo masculino: $72,7 \%$ dos autores são homens e $62,1 \%$ escrevem sobre homens, sendo $71,1 \%$ protagonistas dos romances. Esses

IPOTESI, JUIZ DE FORA, v. 23, n. 2, p. 65-78, jul./dez. 2019 
dados, como dito anteriormente, confirmam que no cenário literário contemporâneo as mulheres não alcançaram o seu espaço, pois a presença feminina como autora de obras é inferior a masculina. Tal resultado permite, por um lado, inferir que as mulheres escrevem menos que os homens e, por outro, perguntar-se se as mulheres realmente escrevem menos ou se a elas simplesmente não foi dado a mesma visibilidade garantida para a autoria masculina. No que se refere ao protagonismo como personagem, assume o papel, na maioria das vezes, de coadjuvante, reiterando novamente o predomínio do masculino no referido sistema.

A pesquisa ainda revela que as mulheres, entre a década de 90 aos anos 2014,

foram retratadas pelos homens como jovens $(42,3 \%)$, adultas $(50 \%)$, belas $(42,3 \%)$, atraentes $(50 \%)$ e inteligentes $(34 \%)$. As mulheres nos livros, para eles, são em boa parte donas de casa, $42,3 \%$ delas são menos intelectuais e dependem mais dos homens financeiramente nessas histórias (BRASIL, 2016).

No entanto, quando o livro era escrito por elas, no mesmo período, $63 \%$ das personagens femininas possuíam como característica principal a inteligência, 22,6\% tinham mais escolaridade que seus esposos, tornando-se mais independentes nas histórias narradas. Nessa linha da representatividade, vale lembrar que, de acordo com dados do IBGE (2014), nosso país está constituído por $51,5 \%$ de mulheres, ou seja, a maioria da população brasileira é feminina. Saindo do território brasileiro e ampliando para o universo hispano-americano, na Argentina, por exemplo, os números não se distanciam muito em relação ao Brasil. Segundo site oficial do órgão de pesquisa Datosmacro.com, em 2017, 51,6\% da população é feminina e $48,94 \%$, masculinaiii.

Continuando em torno dos países hispano-americanos, a invisibilidade das mulheres na literatura não é tão diferente em comparação ao Brasil. Para exemplificar, podemos tomar a história do denominado "Boom hispano-americano", considerado um movimento de autores masculinos, porque, mesmo existindo várias mulheres escrevendo e publicando suas obras, não conta com a presença de escritoras mulheres, somente no "Pós-boom" há a referência a obras de autoria feminina. Seguindo no mundo hispano, conforme estudos, a presença da escrita feminina começa com Sor Juana de la Cruz, mulher mexicana que consegue, no século XVII, iniciar esse movimento feminino e causar indignação ao tratar, em seus poemas, questões referentes à política, à religião e aos desejos intrínsecos que para época eram temas inconcebíveis para serem explorados por uma mulher.

O que se pode afirmar, no entanto, com o passar do tempo, é que os textos escritos por mulheres foram ganhando espaço, visibilidade e reconhecimento no meio literário, mostrando e revelando a face do feminino representado na escrita. Reiterando: a partir do século XX a literatura de autoria feminina, que já existia, ganha força, ou seja, vai se conformando um 'mundo' em que a mulher encontra a possibilidade de ocupar espaços além do doméstico ou de reprodutora humana porque, graças às campanhas anteriores ${ }^{\text {iv }}$, vai revelando-se $\mathrm{e}$ alcançando cargos nos mais diversos setores e conquistando independência social e financeira. A mulher começa a existir ativamente na sociedade como protagonista de sua própria história também na escrita. É na escrita, conforme Cixous (1997), que as mulheres encontram um meio de libertação, de reconhecimento e de descobertas de si mesmas, corroborando com as distintas formas de atuação que alcança essa multiplicidade de vozes femininas na literatura. Essas vozes que estavam, de acordo com Gutiérrez, "ausentes de um cânon quase exclusivamente masculino e predominantemente do primeiro mundo, europeu e da classe dirigente" (GUTIÉRREZ, 2004, p.33) agora estão presentes e não há volta, mesmo que ameaçadoras, como explica Colasanti (1997, p. 41): a escrita produzida por mulheres pode ter caráter ameaçador, pois a linguagem utilizada é individual, rompendo com as normas e problematizando o estabelecido, ou seja, a mulher escritora torna-se uma questionadora ao

IPOTESI, JUIZ DE FORA, v. 23, n. 2, p. 65-78, jul./dez. 2019 
produzir literatura, pois, como "criadoras, elas escapam ao controle, se transformam em ameaça” (COLASANTI, 1997, p.40).

Colasanti, em seu olhar sobre a escrita de mulheres, tenta compreender por que é rotineira a pergunta sobre a existência de uma literatura feminina. Ao indagar-se "por que perguntam se existimos", responde:

Não vou mais aceitar essa pergunta como se aceitam as perguntas que esperam resposta. Recuso-me a procurar novos e, quem sabe, mais convincentes argumentos. $\mathrm{Eu}$, que a partir da escrita estou há anos empenhada em construir a arquitetura de uma voz, de uma voz que sendo minha é feminina, declaro-me ofendida pela pergunta. E, em vez de respondê-la, eu a questiono (COLASANTI, 1997, p. 35).

Para a autora, essas perguntas descartam as muitas autoras que existem pelo mundo, gerando dúvidas quanto à qualidade da literatura por mulheres. Para ela,

a sociedade não quer de fato saber se existe uma literatura feminina. O que ela quer é colocar em dúvida a sua existência. Ao me perguntar, sobretudo a mim, escritora, se o que eu faço existe realmente, está afirmando que, embora possa existir, sua existência é tão fraca, tão imperceptível, que é bem provável que não exista (COLASANTI, 1997, p. 37).

Conforme exposto até aqui, confirma-se a necessidade de ainda voltar-se ao assunto da escrita por mulheres, para seguir enfatizando nossa existência, pois estamos incluídas como mulheres e como escritoras, com o propósito de contribuir para a renovação e (re)significação da literatura não só no que se refere ao ideal estético, mas também como veículo e instrumento de crítica social, na linha de Candido, na obra Literatura e sociedade, na qual o autor explica que a "arte é social, é uma comunicação expressiva", pressupondo, por isso, "algo diferente e mais amplo do que as vivências do artista" (CANDIDO, 2000, p. 20). De acordo com o estudioso, ao pensar a função social da literatura, partindo da relação entre a obra, o autor e o público, ela "independe da vontade ou da consciência dos autores e consumidores de literatura" (CANDIDO, 2000, p. 46). O escritor, para Candido (2000, p. 74), "é não apenas um indivíduo capaz de exprimir a sua originalidade (que o delimita e o especifica entre todos), mas alguém desempenhando um papel social, ocupando uma posição relativa ao seu grupo profissional e respondendo a certas expectativas dos leitores ou auditores". Candido destaca, ainda, que

A literatura é um sistema vivo de obras, agindo umas sobre as outras e sobre os leitores; e só vive na medida em que estes a vivem, decifrando-a, aceitando-a, deformando-a. A obra não é produto fixo, unívoco ante qualquer público; nem este é passivo, homogêneo, registrando uniformemente o seu efeito. São dois termos que atuam um sobre o outro, e aos quais se junta o autor, termo inicial desse processo de circulação literária, para configurar a realidade da literatura atuando no tempo (2000, p. 74).

Partindo, portanto, da escrita de autoria feminina e da convicção de que a literatura, enquanto arte, é social e sua expressão é mais ampla que do que as vivências do artista, neste caso, da escritora, o presente texto volta-se para as obras de Selva Almadav, mais especificamente para a Chicas muertas, publicada em 2014, visando mostrar de que maneira se cumpre essa função social na voz dessa jovem escritora argentina e para exemplificar o processo de tomada de espaço da mulher no universo literário. Além disso, apresenta-se, de forma breve, informações acerca da vida e da obra de Selva Almada.

IPOTESI, JUIZ DE FORA, v. 23, n. 2, p. 65-78, jul./dez. 2019 


\title{
Inquietações necessárias
}

A produção literária de Selva Almada ${ }^{\mathrm{vi}}$ e sua ativa participação no sistema literário e seu envolvimento com as questões sociais de seu entorno faz com que sua atuação na esfera social e cultural possa confrontar um conjunto de valores estagnados socialmente e que, ainda quando fazem referência à mulher, apresentam uma visão tópica e banal do feminino. Por isso, presumimos que suas obras se apresentem como um instrumento perscrutador, pois através dos enredos e personagens, bem como nos contextos em que elas estão inseridas, é possibilitado ao leitor o contato com a temática feminina, com os diferentes papeis sociais que a mulher pode exercer e, principalmente, no caso da obra em questão, com a violência sofrida pelas mulheres.

Como o próprio título Chicas muertas, em português brasileiro, Garotas mortas, a autora já indica de forma direta e seca o tema da obra, a qual se conforma em onze capítulos numerados, antecedidos pela dedicatória e por uma epígrafe, pelo Epílogo, no qual, ao final, está sinalizado a data e o local - Buenos Aires, 30 de enero de 2014 (ALMADA, 2014, p. 185) -, seguido dos Agradecimientos (ALMADA, 2014, p. 187). Ao falar sobre o processo de criação de Chicas muertas, em entrevista para El País, Espanha, Almada explica que é um texto originário de acontecimentos verídicos, diferentes das demais obras de sua autoria, e, por isso, exigiu um conjunto de ações que, para "alguns", o romance se caracteriza como não ficção:

Es una novela de no ficción, como le llaman algunos. Hice entrevistas, consulté los expedientes de los casos, revisé la prensa de la época, entrevisté a familiares, jueces y fui a una tarotista que me echara las cartas. Y una vez que hice todo ese trabajo de campo, guardé el material bastante tiempo y cuando apareció una editorial interesada en el libro me puse a escribir. ${ }^{\text {vii }}$

No que se refere à visita à cartomante, como exemplo da ficcionalização do trabalho realizado para a reconstrução dos acontecimentos, a narradora conta como chegou até ela:

\begin{abstract}
Llego a la Señora por recomendación de unos amigos escritores que la consultan cuando deben tomar decisiones importantes. Confían en su buen juicio y en sus cartas de tarot. Cuando la llamo para pedirle una cita, le explico que mi pedido talvez le resulte inusual: no es por mí por quien quiero verla, sino por tres mujeres que están muertas. Me dice que es más habitual de lo que pienso y arreglamos día y hora. Nunca me tiraron las cartas y la idea me pone un poco nerviosa. Tengo miedo de que ella no haya comprendido que no es de mí de quien quiero averiguar cosas si no de María Luisa, Andrea y Sarita. No quiero conocer mi futuro. No quiero que saque a la luz ningún quiste del pasado. (ALMADA, 2014, p. 46).
\end{abstract}

Apesar da preocupação, fica claro, mesmo que ambígua, que a vidente entendeu a necessidade do encontro. Convém destacar que a decisão de buscar esse apoio para auxiliar a elucidar os episódios está em consonância com a experiência da narradora quando, em sua adolescência, acompanhava sua avó ao curandeiro: "De chica, con la abuela también íbamos al curandero, el Viejo Rodríguez. Vivía en un rancho en las afueras del pueblo, cerca del barrio pobre, el Tiro Federal" (ALMADA, 2014, p. 44).

Em La Nación, Argentina, comentando sobre a escrita e a definição da temática de suas obras, Almada afirma que aproveita aquilo que sabe, ou seja, sobre o que conhece e/ou que faz parte de sua memória:

Para mis ficciones manejo con lo que sé. Para Ladrilleros, no necesité investigar: sé cómo vive un homosexual en un pueblito perdido de la Argentina y sé que pasa muy mal. Y en cuanto a la cuestión religiosa de El viento que arrasa, había tenido

IPOTESI, JUIZ DE FORA, v. 23, n. 2, p. 65-78, jul./dez. 2019 
amigas de la infancia de familias católicas cuyos padres se hicieron evangelistas. En un universo que conozco, prefiero trabajar sobre ese recuerdo y después inventar más que ir a ver hoy como es. En cuanto a Chicas muertas, el tema de la violencia contra las mujeres me interesa desde que empecé a darme cuenta de que no era tan natural como se me había aparecido en la infancia y la adolescencia. Mi madre se indignaba con estas cuestiones, pero había un discurso político alrededor de eso. Me siento comprometida con el tema, pero tengo claro que no por haber escrito un libro sobre femicidio soy una especialista. ${ }^{\text {vii }}$

Como revela Almada, a obra Chicas muertas origina-se do interesse sobre o tema da violência contra as mulheres. $\mathrm{O}$ enredo, por meio de uma voz narrativa em primeira pessoa, a própria autora ficcionalizando sua história de vida e de escrita do texto, mescla percepções e recordações pessoais - uma de escrita de si que revela, no início da narrativa, uma conclusão dura e cruel para uma jovem de treze anos: "Yo tenía trece años y esa mañana, la noticia de la chica muerta, me llegó como una revelación. Mi casa, la casa de cualquier adolescente, no era el lugar más seguro del mundo. Adentro de tu casa podían matarte. El horror podía vivir bajo el mismo techo que vos" (ALMADA, 2014, p. 17) - com a (re)construção de três casos de feminicídios entrecruzados por um conjunto de outros ocorrências de violência de gênero como, por exemplo, a de uma moça que estava com casamento marcado, entre as idas e vindas para as provas do vestido de noiva, uma tarde foi sozinha e, ao errar o caminho, foi sequestrada por quatro homens:

\begin{abstract}
No estaba acostumbrada a andar sola, se confundió de dirección (...). Cuando vio venir un coche, pensó que lo mejor era preguntar antes de seguir dando vueltas, perdida. Adentro del vehículo iban cuatro hombres y se la llevaron. Estuvo secuestrada varios días, desnuda, atada y amordazada en un lugar que parecía abandonado. Apenas le daban de comer y de beber para mantenerla viva. La violaban cada vez que tenían ganas. (...) Una noche escuchó que los hombres se marcharon en el auto. Juntó valor, logró desatarse y escapar por la ventanita. Corrió a campo hasta encontró una casa habitada. Allí la auxiliaron (ALMADA, 2014, p. 19).
\end{abstract}

Além dessas histórias envolvendo mulheres sequestradas e violentadas, o fio condutor da narrativa está centrado em assassinatos reais, situadas no contexto dos anos 80 , envolvendo três mulheres jovens: Andrea Danne, de 19 anos, encontrada morta na sua própria cama, no ano de 1986; Maria Luisa, de 15 anos, desaparecida e encontrada em um terreno baldio com o corpo violado e estrangulado no ano de 1983; Sarita Mundín, de 20 anos, desaparecida em 1988, cujos restos foram encontrados meses depois. Outra constatação forte e dolorida por essa voz que (re)constrói os três assassinatos, todos impunes:

\footnotetext{
Tres adolescentes de provincia asesinadas en los años ochenta, tres muertes impunes ocurridas cuando todavía, en nuestro país, desconocíamos el término femicidio. Aquella mañana yo también desconocía el nombre de María Luisa, que había sido asesinada dos años antes, y el nombre de Sarita Mundín, que aún estaba viva, ajena a lo que le ocurriría dos años después. No sabía que a una mujer podían matarla por el solo hecho de ser mujer (ALMADA, 2014, p. 18).
}

Ao recuperar cada um dos assassinatos, apresentando o cotidiano de cada uma das jovens, de suas famílias, ou seja, como viviam, como desapareceram, como se deu o processo de busca, como foram encontradas, como foi a ação policial e judicial, situando-as em seus espaços de convivência com a família, com vizinhos, com amigos e amigas, a narradora vai também traz à tona sua própria história na qual também está presente a imposição masculina validada e autorizada pela sociedade machista. Além do exemplo anterior, a narradora,

IPOTESI, JUIZ DE FORA, v. 23, n. 2, p. 65-78, jul./dez. 2019 
acionando sua memória, escreve que sua mãe contou em várias ocasiões o mesmo episódio ocorrido quando ainda eram recém-casados:

Al poco tiempo de vivir juntos, mientras almorzaban, tuvieron una discusión, alguna tontería de adolescentes, que se fue poniendo acalorada. Entonces mi padre levantó una de sus manos, amagándole una cachetada. Y mi madre, ni lerda ni perezosa, le clavó un tenedor en el brazo que él tenía apoyado en la mesa. Mi padre nunca más se hizo el guapo (ALMADA, 2014, p. 53).

$\mathrm{Na}$ sequência, afirma que não se lembra de nenhuma conversa pontual sobre a violência de gênero nem que sua mãe lhe tenha advertido especificamente sobre o assunto:

Pero el tema estaba presente. Cuando hablábamos de Marta, la vecina golpeada por su marido (...). Cuando hablábamos de Bety, la señora de la despensa que se colgó en el galponcito del fondo de su casa. Todo el barrio decía que el marido le pegaba y que sabía bien porque no se le veían las marcas. Nadie lo denunció nunca. Luego de su norte se corrió la voz de que él la había matado y había tapado todo pasando por un suicidio. Podía ser. También podía ser que ella se hubiera ahorcado, harta de la vida que tenía. Cuando hablábamos de la esposa del carnicero López. (...) Ella lo denunció por violación. Hacía tiempo que, además de golpearla, la abusaba sexualmente. A mis doce años, esa noticia me había impactado muchísimo. ¿Cómo podía ser que el marido la violara? (ALMADA, 2014, p. 54).

Em outras palavras, entre um relato e outro, a narradora Almada, pois estamos diante de uma escrita de si que mescla realidade e ficção, que participa do enredo, reavivando suas lembranças reais ao mesmo tempo que reconstrói os assassinatos que motivaram seu romance, denunciando o silenciamento, pois estamos nos anos 80, da voz dessas mulheres. Assim, nesse processo de reviver tantas situações de violência doméstica e feminicídios, Almada mostra uma sociedade que ainda perde suas mulheres por meio de assassinatos brutais físicos e verbais.

De posse do conteúdo do romance em estudo, convém conhecer um pouco sobre a trajetória dessa autora, cuja literatura "causa arrepios, sem chegar ao aguilhão do horror" ( $E l$ País), e que, considerando Candido, confirma que o escritor, neste texto a escritora, é alguém capaz de exprimir a sua originalidade ao mesmo tempo que desempenha um papel social, ocupando uma posição relativa ao seu grupo profissional e respondendo a certas expectativas dos leitores e leitoras, ou seja, trazendo à tona os dilemas sociais e propiciando uma tomada de consciência do seu entorno: nesta obra a violência contra as mulheres no século XX e sua persistência no século XXI.

\section{Almada por Almada}

Selva Almada nasceu em 1943, em Entre Ríos, uma província da Argentina fazendo fronteira com o Uruguai. Viveu e cresceu no mesmo lugar por 17 anos. Após este período, mudou-se para Buenos Aires. Entretanto, a escritora nunca perdeu o vínculo com o povoado e com as pessoas que vivem nele. Desde pequena já sinalizava a aproximação com a escrita, pois, segundo entrevista concedida à La Hora ${ }^{i x}$, Almada gostaria de ser jornalista e, com esta vontade, criou um jornal de escola em Villa Elisa. A partir deste jornal escolar, a vocação de escritora, a facilidade de contar histórias a condicionou ao curso de Comunicação, na cidade de Paraná. Descobriu a paixão pela narrativa de ficção e buscou a formação no curso de graduação em Letras e em oficinas literárias. Daí nasce uma das mais respeitadas vozes da nova literatura argentina.

IPOTESI, JUIZ DE FORA, v. 23, n. 2, p. 65-78, jul./dez. 2019 
Ao comentar sobre as oficinas criativas, Selva Almada afirma não acreditar que se pode ensinar a escrever, mas sim ajudar a melhorar a produção do texto:

\begin{abstract}
No creo que un taller te enseñe a escribir. Te puede enseñar a mejorar la escritura, a encontrar tu propia voz, tus propios universos. Pero después, hay algo con lo que se nace, que es el talento -llamémosle- y eso es lo que hace que un escritor sea diferente de otro (ALMADA, 2019).
\end{abstract}

Movida pela preocupação com a publicação e divulgação da literatura contemporânea argentina, a autora participa da criação da editora chamada Carne Argentina, na qual se permitem espaços para novos escritores, uma vez que, de acordo com Almada, "Gran parte de la diversidad que tiene la literatura argentina contemporánea se debe a las editoriales independientes, que abrieron el espacio para publicar". (ALMADA, 2019).

Em relação ao conjunto de suas obras, chama a atenção a presença do espaço rural em praticamente todos os seus textos. Ao falar sobre isso, Almada diz que

Lo que tienen esos sitios pequẽ̃os es que hay una violencia con la que una convive
que está naturalizada" e complementa que "hay una cuestión de esconder las cosas,
de muchos secretos, y creo que el secreto y la violencia cotidiana son temas muy
atractivos para la literatura (ALMADA, 2019).

Sobre a temática abordada na produção literária de Almada, uma delas é o feminicídio. A autora, a esse respeito, afirma que a ela interessa a criação ficcional e que a ficção está relacionada com o contexto e também com o que os leitores buscam em relação a sua época:

\begin{abstract}
tampoco me gustaría que todo lo que yo escriba tenga que ver con el tema o que el tema esté antes que la historia de los personajes. Me interesa seguir escribiendo ficción, y la ficción siempre es leída de acuerdo a los tiempos, con el contexto y con lo que los lectores buscan en el texto (ALMADA, 2019).
\end{abstract}

Nessa mesma reportagem, seguindo no tema do feminicídio, Almada lembra as críticas que tem sofrido por parte de algumas pessoas que não aceitam a nova literatura gerada por mulheres e a classifica quanto a "quotas de gênero" ou "moda". A autora reage explicando que geralmente essas críticas provêm do sexo masculino e que, se reclamam, é porque estão percebendo a perda de espaço que antes era ocupado totalmente por eles. Reitera, ainda, que

\footnotetext{
Es fácil echarle la culpa al feminismo en vez de pensar: 'bueno, por qué interesa tanto la literatura de estas mujeres'. Quizás porque están haciendo cosas mucho más creativas, más arriesgadas y yendo por temas y universos que no han transitado los escritores varones. No es porque sean mujeres, sino porque realmente son muy buenas escritoras. Es fácil decir que es porque el feminismo las puso de moda, en vez de leer los textos más objetivamente (ALMADA, 2019).
}

Buscando mostrar um pouco mais sobre a criação literária de Almada, mais especificamente sobre a obra em estudo, continuando com a voz da própria escritora, convém recuperar sua entrevista concedida ao Canal de la Ciudad, intitulado Chicas Muertas - Selva Almada (2015), por meio da qual retomamos sua motivação para tematizar, em Chicas Muertas, além do feminicídio, as pequenas formas de violências cotidianas que as mulheres sofrem todo o tempo e não percebem, conforme já mencionado, quando relata situações ocorridas com distintas personagens e também com ela mesma, já que ela, escritora, se assume também como personagem narradora. Um dos pontos da entrevista diz respeito à violência no espaço rural, sobre o qual Almada salienta que, principalmente, no campo, onde

IPOTESI, JUIZ DE FORA, v. 23, n. 2, p. 65-78, jul./dez. 2019 
as mulheres têm menos informação, não têm a quem recorrer quando agredidas e, em alguns casos, nem ao menos se dão conta das agressões veladas no dia a dia. A escritora afirma também que, muitas vezes, as mulheres também reproduzem os padrões machistas que a sociedade impõe devido à criação familiar de cada uma.

Seguindo no tema da violência e recuperação dos três assassinatos, ao ser perguntada sobre a reação dos familiares das meninas ao relembrar esses casos, a escritora é taxativa ao dizer que "son casos de más de treinta años y no se espera que sean resueltos. Pero es un registro de que esas chicas vivieron y fueron asesinadas. Eso de alguna forma reconforta sus amigos y familia" (ALMADA, 2015).

Ela ainda ressalta que este libro é para o cidadão em geral, pois o tema nele abordado é duro, mas o mais importante é que estamos refletindo sobre os casos de feminicídios que ocorrem em todos os lugares e em todas as épocas. A escritora complementa dizendo que, neste caso, a literatura se confirma como uma arma social, porque, por meio dela, é possível alertar uma grande parte da população para este tipo de crime. Admite, ainda, que: "todo lo que puedo escribir para pensar sobre el tema, lo voy a hacer (...) Soy feminista y activista, y si el libro es un vehículo para eso, ifantástico!” (ALMADA, 2015).

No que diz respeito à presença de Almada na narrativa Chicas muertas, ou seja, o "eu" narradora ser o mesmo da "eu" da autora, essa inserção já se revela na abertura do romance "A manhã de 16 de novembro de 1986 estava limpa, sem uma nuvem, em Villa Elisa, a terra onde nasci e me criei, no centro-leste da província de Ente Ríos".(ALMADA, 2014, p. 13, grifo nosso). Além disso, em entrevista realizada em 02/10/2017, pela revista portuguesa Í́psilon ${ }^{\mathrm{x}}$, intitulada "Selva Almada pergunta porque é que se morre só por se ser mulher", com o subtítulo "Selva Almada encontrou uma voz de tremenda crueza poética para contar a morte de três adolescentes. É um livro onde a escritora põe a sua biografia para dizer que podia ser ela. Que foi sorte não ser ela. Raparigas Mortas pergunta porque é que se morre só por se ser mulher", Almada fala sobre a constituição do livro de Chicas muertas / Raparigas mortas $^{x i}$, dizendo que "Não há nada de ficção neste livro. O que acontece é que se está a contar um facto real, uma investigação, com os recursos da literatura. Isso dá ao livro um ar novelesco, contar com elementos que não vêm do jornalismo, mas da literatura" (ALMADA, 2017).

Ela confessa à entrevistadora que essa obra a tocou profundamente: "Sinto que o decurso de tudo isso e a escrita se repercutiram na minha vida pessoal". Explica também, na mesma fala, o que a palavra feminicídio significa para ela:

Como da primeira vez em que a ouvi chamou-me a atenção e depois me pareceu-me tão óbvia; se havia uma palavra como homicídio teria de haver outra, femicídio. Tenho essa palavra completamente interiorizada. Mas custa dizer e escrever femicídio, custa que esses crimes só possam acontecer a uma mulher e não a um homem. Essa palavra refere-se a uma coisa muito mais pontual do que homicídio. Alerta-me para uma descoberta tardia que fiz, é muito chocante dar-me conta de que somente pelo facto de se ser mulher se pode sofrer ataques. De homens ou de outras mulheres. Há mulheres criadas no machismo, porque isso fazia parte de uma cultura (ALMADA, 2017)

Esta mesma ideia já foi dada em entrevista ${ }^{x i i}$ audiovisual concedida à Trilha de Letras, na TV Brasil, onde Almada analisa como eram educadas as meninas do interior e relembra:

Desde pequeña nos venían diciendo que había que cuidarse de los extraños que, no deberían hablar con hombres que no conocían (...) ni pasar en determinados lugares a ciertas horas. La seguridad siempre estaba para la mujer dentro de su casa. Era una manera de adoctrinamiento también como mantenemos nosotras las mujeres dentro de la casa. (...) y el crimen de Andrea $a^{\text {xiii }}$ venía a decir todo lo

IPOTESI, JUIZ DE FORA, v. 23, n. 2, p. 65-78, jul./dez. 2019 
contrario. Venía decir que adentro de tu casa tan poco está segura (ALMADA, 2018).

O que Selva Almada reflete no trecho anterior recai na possibilidade de segurança que a mulher poderia ter, ou seja, se nem na sua própria casa, lugar que sempre foi cultuado como o local mais seguro e puro para uma mulher, qual o outro lugar que ofereceria segurança? Essa e outras reflexões próprias da obra de Almada que nos oportunizam uma dose de realidade e, ao mesmo tempo, (re)significações pessoais e sociais em torno de questões relativas ao ser/Ser humano.

Apresentamos Selva Almada, escritora argentina contemporânea, ocupando seu espaço e lutando pelo reconhecimento de sua literatura, que, por meio de sua obra, neste artigo, especificamente, Chicas muertas, ao retratar três assassinatos reais, alerta o leitor e a leitora sobre ao que estão expostas as mulheres pelo simples fato de serem mulheres. Nesse sentido, a Literatura, sem dúvida, é o veículo no qual é possível encontrar um elo entre o que é velado e o que pode ser revelado. É uma senha de acesso ao mundo, muitas vezes idealizado, mas ainda escondido, oprimido. Por isso, a Literatura torna-se essencial na formação de vida de qualquer sujeito, contribuindo para sua construção crítica e significativa de mundo.

Assim, para finalizar, em consonância com o propósito deste texto, convém reiterar que a literatura de autoria feminina, especificamente, torna-se uma estratégia de defesa, um escudo ou um artifício elaborado com uma das formas mais poderosas de lutar, com as palavras. Portanto, não deixemos de ouvir as vozes femininas que emergem das letras literárias de forma incisiva, que marcam esse movimento literário que se faz na atualidade.

\title{
CHICAS MUERTAS, BY SELVA ALMADA: THREE MURDERS AND THE SILENCING OF VIOLENCE AGAINST WOMEN
}

\begin{abstract}
This article provides the analysis of the work Chicas muertas (2014), by Selva Almada, in order to show how the social function of art is fulfilled, according to Candido (2000), in the voice of this Argentine writer and it also indicates as an example of the occupation process of space by woman in the literary universe. Biographic data are also presented as the writer is herself included in the fictional her own work.
\end{abstract}

Keywords: Female authorship. Selva Almada. Chicas muertas.

\footnotetext{
Notas explicativas

'Trecho originário do texto "Feminismo activo" (1911), de João do Rio, e extraído do artigo "Para além do cânone", de Elódia Xavier, que compõe na obra Literatura e feminismo: propostas teóricas e reflexões críticas, organizada por Cristina Ramalho, publicada pela editora Elo, em 1999.

ii Disponível em: http://www.cultura.gov.br/noticias-destaques/ /asset_publisher/OiKX3xlR9iTn/content/naliteratura-a-mulher-ainda-nao-alcancou-protagonismo/10883. Acesso em: 06 out. 2018.

iii DATOSMACRO, Argentina. Em: https://datosmacro.expansion.com/demografia/poblacion/argentina. Acesso em: 07 out. 2018.

iv No decorrer do século XIX, de forma mais efetiva a partir da metade do século XIX, várias mulheres ocupam espaço no jornalismo criando, inclusive, seus próprios periódicos para defender seus direitos, estando, em primeiro lugar, a educação; em segundo, o direito à profissão e, posteriormente, o direito ao voto, como revela
}

IPOTESI, JUIZ DE FORA, v. 23, n. 2, p. 65-78, jul./dez. 2019 
Constância Lima Duarte na obra Imprensa feminina e feminista no Brasil: século XIX: Dicionário ilustrado, publicada pela editora Autêntica, em 2016.

` Nascida em Entre Rios, Argentina, em 05/04/1973. Entre suas publicações, seguindo ordem cronológica, destacam-se: em 2003, Mal de muñecas, (poesia); em 2005, Niños (novela); em 2007, Una chica de província (contos); em 2012, El viento que arrasa (romance); em 2012, Intemec (relatos); em 2013, Ladrilleros (romance); em 2014, Chicas muertas (crônicas); em 2015, El desapego es una manera de querernos (cuentos); em 2017, El mono en el remolino: Notas del Rodaje de Zama de Lucrecia Martel (relatos).

${ }^{v i}$ Obras da escritora argentina Selva Almada fazem parte do corpus de análise da tese (2019-2022) de Maria Edilene de Paula Kobolt, desenvolvida na PUCRS, bolsista pela CAPES.

vii Entrevista a El Pais em 16/09/2015, intitulada "Selva Almada, la escritora rural que sale al mundo", disponível em https://elpais.com/cultura/2015/09/16/actualidad, acesso em 24 jun. 2019.

viii Publicado em La Nación em 02/02/2015, intitulada "Selva Almada: "Yo no hago documentalismo literario con mis novelas", disponível em https://www.lanacion.com.ar/cultura/selva-almada-yo-no-hagodocumentalismo-literario-con-mis-novelas-nid1764961, acesso em 24 jun. 2019.

${ }^{\text {ix }}$ Publicado em La Hora em 28/06/2019, intitulada "Selva Almada: la nueva escritora visitante del Centro Cultural Benjamín Carrión disponível” em https://www.lahora.com.ec/noticia/1102254066/selva-almada-lanueva-escritora-visitante-del-centro-cultural-benjamin-carrion, acesso em 24 jun. 2019.

${ }^{x}$ Publicado na revista ípsilon em 02/10/2017, intitulada "Selva Almada pergunta porque é que se morre só por se ser mulher", em https://www.publico.pt/2017/10/02/culturaipsilon/entrevista/o-corpo-sacrificial-de-umamulher-1786696. Acesso em 24 jun. 2019.

${ }^{x i}$ Para esclarecimento: as obras de Selva foram traduzidas em diversas línguas. Neste trecho do texto utilizamos o título da obra em duas línguas Raparigas mortas (em português de Portugal) e Chicas muertas (título na língua original).

xii Publicado Trilha das Letras-TV Brasil em 21/08/2018, intitulada "Selva Almada fala sobre Feminicídio", em https://www.youtube.com/watch?v=8kwJJz-7ZvU\&t=5s .Acesso em 24 jun. 2019.

xiii Almada se refere a um dos crimes tratados na obra Chicas muertas. A personagem Andrea morreu dentro de sua casa, com uma punhalada em seu coração.

IPOTESI, JUIZ DE FORA, v. 23, n. 2, p. 65-78, jul./dez. 2019 


\section{Referências}

ALMADA, Selva. Biografia. Disponível em:

https://www.portaldaliteratura.com/autores.php?autor=3049 . Acesso em: 08 out 2018.

ALMADA, S. Chicas muertas. Youtube, 13 nov. 2015. Disponível em

$<$ https://www.youtube.com/watch?v=LBpESnvgTHk\&t=28s>. Acesso em: 08 jun.19

BEAUVOIR, Simone de. O segundo sexo: a experiência vivida. Tradução Sérgio Milliet. São Paulo: Difusão Européia do Livro, 1967. Disponível em:

<http://brasil.indymedia.org/media/2008/01/409680.pdf>. Acesso em: 08 out. 2018.

BONNICI, Thomas. Teoria e crítica literária feminista: conceitos e tendências. Maringá: EDUEM, 2007.

BRAH, Avtar. Diferença, diversidade, diferenciação. Cadernos Pagu, Campinas, n. 26, p. 329-376, jan./jun. 2006.

BRASIL, Ministério da Cultura. (2016). Disponível em: http://www.cultura.gov.br/noticiasdestaques//asset_publisher/OiKX3xIR9iTn/content/na-literatura-a-mulher-ainda-naoalcancou-protagonismo/10883. Acesso em: 06 out. 2018.

BUTLER, Judith. Problemas de gênero: feminismo e subversão da identidade. Rio de Janeiro: Civilização Brasileira, 2003.

CANDIDO, Antonio. Literatura e sociedade: estudos de teoria e história literária. 8. ed. São Paulo: T. A. Queiroz, 2000.

CIXOUS, Hélène. The laugh of the Medusa. [1975]. In: WARHOL, Robyn R.; HERNDL, Diane P. Feminisms: an anthology of literacy theory and criticism. New Jersey: Rutgers University, 1997.

COLASANTI, Marina. Por que nos perguntam se existimos. In: SHARPE, Peggy (org.). Entre resistir e identificar-se: para uma teoria da prática da narrativa brasileira de autoria feminina. Florianópolis: Mulheres; Goiânia: UFG, 1997. p. 33-42.

CULLER, Jonathan. Sobre a desconstrução: teoria e crítica do pós-estruturalismo. Tradução Patrícia Burrowes. Rio de Janeiro: Record; Rosa dos Tempos, 1997.

CUNHA, Glória da (org.). La narrativa histórica de escritoras latino-americanas. Buenos Aires: Corregidor, 2004.

DATOSMACRO, Argentina. Disponível em:

https://datosmacro.expansion.com/demografia/poblacion/argentina. Acesso em: 07 out. 2018.

DE LA CRUZ, Sor Juana Inés. Respuesta de la poetisa a la muy ilustre Sor Filotea de la Cruz, 1691. Antología del Ensayo. Disponível em:

http://www.ensayistas.org/antologia/XVII/sorjuana/sorjuana1.htm . Acesso em: 18 out. 2018.

IPOTESI, JUIZ DE FORA, v. 23, n. 2, p. 65-78, jul./dez. 2019 
DEL PRIORE, Mary. História das mulheres: as vozes do silêncio. In: FREITAS, Marcos Cezar (org.). Historiografia brasileira em perspectiva. 4. ed. São Paulo: Contexto, 2001. p. 217-235.

DEL PRIORE, Mary (org.). História das mulheres no Brasil. 9. ed. São Paulo: Contexto, 2008.

GARFINKEL, Harold. Passing and the managed achievement of sex status in an 'intersexed' person [1967]. In: STRYKER, S.;WITTLE,S. (orgs.). The transgender studies reader.

Londres: Routledge, 2006.

GUTIÉRREZ ESTUPIÑÁN, Raquel. Una introducción a la teoría literario feminista. México: Instituto de Ciencias Sociales y Humanidades Benemérita Universidad Autónoma de Puebla, 2004.

HARAWAY, Donna. "Gênero" para um dicionário marxista: a política sexual de uma palavra. Cadernos Pagu, Campinas, n. 22, p. 201-246, jan./jun. 2004.

HERNANDES, Luciana Carneiro. Tecidos e tessituras: representação do feminino em María Rosa Lojo. 2017. 205 f. Tese (Doutorado em Letras - Área de Literatura e Vida Social) Faculdade de Ciências e Letras, Universidade Estadual Paulista Júlio de Mesquita Filho, Assis, 2017.

RAPUCCI, Cleide Antonia. Mulher e deusa - a ideia do feminino. In: . Mulher e deusa: a construção do feminino em Fire works de Angela Carter. Maringá: EdUem, 2011. p. 55-135.

RUBIN, Gayle; BUTLER, Judith. Tráfico sexual: entrevista. Cadernos Pagu, Campinas, n. 21, p. 157-209, 2003. Disponível em: http://www.scielo.br/scielo.php?script=sci_arttext\&pid=S010483332003000200008\&lng=pt \&nrm=iso. Acesso em: 06 out. 2018.

RUBIN, Gayle. $O$ tráfico de mulheres: notas sobre a economia polìtica do sexo. Tradução Christine Rufino Dabat, Edileusa Oliveira da Rocha e Sonia Corrêa. Recife: S.O.S Corpo, 1993. Disponível em: https://repositorio.ufsc.br/handle/123456789/1919. Acesso em: 06 jan. 2018.

SCHMIDT, Rita Terezinha. Repensando a cultura, a literatura e o espaço da autoria feminina. In: NAVARRO, Márcia Hoppe (org.). Rompendo o silêncio: gênero e literatura na América Latina. Porto Alegre: UFRGS, 1995.

SCHMIDT, Rita Terezinha. Para além do dualismo natureza/cultura: ficções do corpo feminino. Revista Organon, Porto Alegre, UFRGS, v. 27, n. 52, 2012. Disponível em: http://seer.ufrgs.br/index.php/organon/article/view/33480/21353. Acesso em: 09 out. 2018.

SCHMIDT, Rita Terezinha. Refutações ao feminismo: (des)compassos da cultura letrada brasileira. Estudos feministas, Florianópolis, v. 14, n. 3, p. 272, set-dez/2006. Disponível em: http://www.scielo.br/pdf/ref/v14n3/a11v14n3.pdf. Acesso em: 09 out. 2018. 
SHOWALTER, Elaine. A literature of their own: British women novelists from Brontë to Lessing. Princeton: Princeton University, 1998.

SILVA, Tânia M. Gomes. Trajetória da historiografia das mulheres no Brasil. Politeia, História e Sociedade, Vitoria da Conquista, v. 8, n. 1, p. 223-231, 2008. Disponível em: http://periodicos.uesb.br/index.php/politeia/article/viewFile/276/311 . Acesso em: 05 out. 2018.

XAVIER, E. Para além do cânone. In: RAMALHO, C. (org.) Literatura e feminismo: propostas teóricas e reflexões críticas. Rio de Janeiro: Elo, 1999. p. 15-22.

ZOLIN, L. O. Literatura de autoria feminina. In: BONNINI, T.; ZOLIN, L. O. (orgs.) Teoria literária: abordagens históricas e tendências contemporâneas. Maringá: Eduem, 2012. p. 327336.

Data de submissão: 30/06/2019.

Data de aceite: $30 / 08 / 2019$. 